\title{
Metodologias Ativas Para Formação Profissional Do Pedagogo: Uma Experiência Vivida Na Faculdade Eniac
}

\author{
Active Methodologies for Vocational Training of Educator: An \\ experience in College Eniac
}

Simone Cristina Gonçalves Vianna1, Álvaro Fernando Rodrigues da Cunha²

\begin{abstract}
1.Simone Cristina Gonçalves Vianna é Mestre em Educação pela Universidade Cidade de São Paulo - UNICID (2011). Especialista em Redes de Computadores pelo Laboratório de Arquitetura e Redes de Computadores da Escola Politécnica da Universidade de São Paulo LARC/USP (2003). Especialista em Docência no Ensino Superior pela Universidade Cidade de São Paulo - UNICID (2010). É Bacharel em Ciência da Computação pela Universidade São Judas Tadeu - USJT (1999). E-mail <simone.vianna@eniac.com.br>.

2.Álvaro Fernando Rodrigues da Cunha, E-mail Atual Prof Pesquisador da Aliant International University San Diego - Califórnia - EUA. Pós-doutor em etno-antropo-linguística. Unicamp. Doutor e Mestre em Língua Portuguesa. USP. Graduado em Letras. Universidade da Amazônia. Prof Cientista da Unicamp na criação da TeCOE® -Teoria de Cruzamento em Oralidade e Escrituralidade em 2013. Pesquisador no Laboratório de Estudos sobre Etnicidade, Racismo e Discriminação - LEER-USP. E-mail <dr.alvarocunha@gmail.com>
\end{abstract}

\section{Resumo}

No âmbito acadêmico atual existe uma da demanda pelo uso das "Metodologias Ativas" para a formação profissional. Esta pesquisa compartilha uma das experiências vividas no Curso de Pedagogia da Faculdade Eniac FAPI, na formação de futuros pedagogos, a partir deste processo. Ele trata do significado de se formar um profissional. Das verdadeiras demandas do mundo do trabalho, especificamente deste tipo de trabalho. Do papel dos atores envolvidos - neste caso da instituição de ensino, dos professores, do tipo de aluno nesta formação profissional, e do modus operandi, o como formar este profissional capaz de lidar com as demandas especificas do ensino.

Palavras chave: Metodologias Ativas, Formação Profissional, Pedagogia do Sujeito

\begin{abstract}
Under the current academic, there is a demand for the use of "active methodologies" for vocational training. This research shares of experiences of the Pedagogy Course of School Eniac FAPI, in the training of future pedagogues, from this process. It deals with the meaning of form a professional. Of the real demands of the world of work, specifically of this type of work. The role of the actors involved - in this case the institution of education, of teachers, of the type of student in this professional training, and the modus operandi, how to form this professional capable of dealing with the specific demands of teaching.
\end{abstract}

Keywords: Active methodologies, Vocational Training, Pedagogy of Subject 


\section{Introdução}

O objetivo geral da pesquisa "Metodologias Ativas para formação profissional do Pedagogo: uma experiência vivida na Faculdade Eniac" é saber porque existe uma demanda acadêmica pelo uso das Metodologias Ativas. $\mathrm{O}$ objetivo específico é conhecer a formação deste profissional que trabalha para atender esta demanda. Por este motive, nesta investigação se compartilha uma experiência vivida no Curso de Pedagogia da Faculdade Eniac FAPI na formação de pedagogos, a partir deste processo de formativo tão peculiar. Ele trata do significado de se formar um profissional com esta atitude.

O problema que se discute é: se existe uma verdadeira demanda no mundo do trabalho por este profissional, e especificamente, por este tipo de trabalho e do papel dos atores envolvidos - neste caso da instituição de ensino, dos professores, do tipo de aluno nesta formação profissional, e do modus operandi, o como formar este profissional capaz de lidar com as demandas especificas neste tipo de ensino.

Justificativa: sabe-se que as instituições de ensino precisam de profissionais da educação e precisam "formar" profissionais aptos para trabalhar com as especificas demandas da educação. Diante deste entendimento, muitos questionamentos são feitos, dentre eles:

I) O que significa "formar"?
II) II) Quais são as verdadeiras demandas do mundo do trabalho?

III) III) Qual o papel dos atores envolvidos - instituição de ensino, professor, aluno - na "formação" profissional? E, mais,

IV) IV) Como "formar" profissionais capazes de lidar com estas demandas?

Hipóteses: acredita-se que se respondidas as questões referentes à formação dos futuros pedagogos, a partir deste processo que trata do significado de se formar um profissional com o foco nas verdadeiras demandas do mundo da educação, do papel dos atores envolvidos no modus operandi deste processo, como no caso estudado em uma instituição de ensino, os novos professores formados possam atingir o interesse e aumentar o desempenho dos formandos. Além de formar profissionais capazes de lidar com as demandas especificas do ensino atual. Pois não basta apresentar respostas prontas para os questionamentos. Assim, cumpre a este estudo que relata uma experiência, compartilhá-las com as teorias e seus autores.

A metodologia utilizada para a compreensão desta formação contou com a pesquisa de campo na análise dos conceitos 
aplicados nas salas de aula, da dinâmica dos professores, e as pesquisas bibliográficas e eletrônicas.

O Referencial teórico nesta pesquisa analisou os seguintes conceitos e autores: compreensão da língua portuguesa pelo viés de Michaelis (2009). A administração nos novos tempos pelo olhar de Chiavenato (2004). A psicologia da educação virtual, o como aprender e ensinar com as tecnologias da informação e da comunicação de pelo foco de Coll e Monereo (2010), além da análise de boletins eletrônicos e observação da gestão do conhecimento de Bookman (2004).

\section{Formação Profissional Para Atuar Com Metodologias Ativas}

Com este relato, pretende-se promover espaço para a reflexão das primordiais questões que aventam a "formação" de profissionais aptos para atender as demandas do atual mundo do trabalho a partir da educação. Explicar o significado de "formar" e seus derivados. Formar, em sentido amplo, significa, segundo Michaelis, (2009. p.63). Dar a forma natural a, fabricar, fazer. Constituir, produzir física ou moralmente, dispor em certa ordem, ou em linha. Com base na significação exposta é possível entender a "formação" como um processo de fabricação qualquer, no sentido daquilo que se faz para a construção de um produto ou objeto, incluindo suas funções específicas e modus operandi.
O homem é um ser racional, com capacidades, motivações e desejos que lhes são próprios. Impossível "formá-lo" a partir deste entendimento, como se este fosse um objeto produzido em série, a exemplo de tantos produtos que são feitos em linhas de produção fabris.

Assim, diante desta concepção, justifica-se, pois, o uso do verbo "formar" e seus derivados entre aspas, para indicar sentido figurado, sugerindo um significado que está além de seu literal. O "formar" para a educação profissional precisa ser compreendido como uma ação que vem de dentro para fora, que está sujeita, obrigatoriamente, à capacidade de lidar com conhecimentos quaisquer, mas, do mesmo modo, sujeita à aspiração, à disposição e à necessidade daquele que se "forma".

A "formação" profissional de sujeitos hábeis e competentes, preparados para atuar com eficácia, no atual mundo do trabalho, precisa ser arquitetada como movimento que inclui descoberta, inovação, imersão e transformação. Precisa, além disto, ser praticada a partir de determinado contexto, de modo a promover espaço para que alunos e professores se reconheçam e se estabeleçam sujeitos profissionais competentes, responsáveis e, por que não dizer com felizes. O que ensinar? Uma resposta a apresentar talvez fosse: aquilo que atenda às tais verdadeiras demandas do atual mundo do trabalho. Mas, quais são mesmo estas demandas? Por que ensinar este ou aquele conteúdo de ensino? Porque o conteúdo faz parte dos currículos da maioria das instituições de 
ensino. Por estar descrito nas diretrizes curriculares de determinados cursos ou áreas. Um conteúdo de ensino que ressalta um tema pode, até mesmo, não ser necessário às atuais demandas no mundo do trabalho de tal formação. Ou por fazer parte de raciocínio que possa levar o outro a descobrir, a inovar, a imergir e a transformar o sujeito profissional em formação, competente, socialmente responsável e satisfeito com sua atuação.

A vida há tempos, em ambientes de rápidas, profundas e urgentes transformações exige, continuadamente que, em curtos espaços de tempo, a concepção, a produção e consequente a utilização de novos produtos e/ou serviços.

Para produzir ou, coexistir a partir deste dinamismo e desta urgência faz-se premente uma "formação", que garanta aos "formandos" a capacidade de descobrir, inovar, imergir e transformar, imediatamente, ou futuro rápido, durante o período "formativo" ou imediatamente após. Tal performance é difícil e questionamentos, em geral, acaloram as discussões de professores, coordenadores de curso, diretores acadêmicos, orientadores educacionais, facilitadores, mediadores e outros profissionais que atuam no âmbito da Educação. Mas, não existe um guia, manual ou tutorial de como fazê-lo. Tampouco, uma lista pronta e acabada com todos os recursos que se pode utilizar no caminhar da "formação" destes profissionais. O uso de Metodologias Ativas de ensino e aprendizagem em espaço acadêmico, no entanto, tem sido largamente debatido como um dos elementos que se pode empregar para o alcance desta necessidade.

Como o próprio nome sugere, trata-se de um método de ensino e aprendizagem ativo que remete à ideia de movimento, seja este um movimento de descoberta, de inovação, de imersão e/ou de transformação. Imbricado nestes movimentos, existem outros como a comunicação, para a integração, a colaboração para reflexões, individuais e coletivas, que pressupõem uma relação de ensino e de aprendizagem e um ambiente "formativo" diferentes dos tradicionais.

$\mathrm{Na}$ expectativa de participar acontecem erros, acertos, rearranjos e compartilhamentos. Momentos de "formação" inéditos e/ou vivenciados anteriormente que passam a fazer parte dos resultados, assim, com ênfase no como fazer, se dá a prática das metodologias ativas para a "formação" do pedagogo graduando pela Faculdade Eniac 2015.

Embora as Metodologias Ativas não tragam em seu bojo a obrigatoriedade de serem trabalhadas a partir de tecnologias computacionais inovadoras, esta instituição, explana sobre a aplicação destas metodologias subsidiadas pela tecnologia. Elas se fazem presentes e são consideradas como ferramentas, segundo Demo (2008), “aparatos" computacionais que auxiliam nas descobertas, inovações, imersões e transformações do formando. O século XXI exige novas habilidades das pessoas e a sociedade, em especial das novas 
alfabetizações descortinam as tradicionais remanejadas sob a influência tecnológica”.

Coloca, ainda, que "o atraso da pedagogia é astronômico, o que não lhe permite direcionar a tecnologia; ao contrário, fica a reboque dela". Como resposta, aponta que é preciso "continuar fazendo a velha pedagogia com as tecnologias mais novas" (Senac, 2008, p.5).

A formação permanente e a tecnologia de Pedro Demo (2014) contrapõem a velha pedagogia e analisando-se esta contraposição se entende a necessidade de se fazer, ao invés da velha, a nova pedagogia com a ajuda, das tecnologias digitais.

Sobre a "velha pedagogia", citada por Demo (2014), entende-se ser possível concebê-la à luz do tradicional processo de ensino e aprendizagem, em que o foco está naquele que, supostamente, ensina - o professor, aquele que cumpre a responsabilidade pelo aprender do outro - o aluno, como se fosse possível responsabilizar alguém pela aprendizagem de outrem como se este fosse uma tabula rasa.

Que saia a velha e entre a nova pedagogia. Esta última, por sua vez, trabalhada a partir de Metodologias Ativas de ensino e aprendizagem que coloquem: aluno; como o protagonista de sua própria formação e professor; como o facilitador, orientador, mediador ou promotor desta "formação". Uma nova pedagogia, subsidiada, pois, por tecnologias digitais inovadoras e que permitam, ao mesmo tempo, "formar" e treinar. Trata-se de uma parceria das Metodologias Ativas com as Tecnologias de Informação e Comunicação - TICs, esta, já difundida no cotidiano dos estudantes e professores. Uma parceria que faz com que os futuros pedagogos construam-se hábeis e competentes em sua área de atuação profissional. Tão competente quanto fluente tecnologicamente. Neste sentido, entende-se que as estratégias de ensino e aprendizagem devem promover espaço para que o aprendizado se faça de modo cada vez mais autônomo, preparando estudantes a intervirem nas mais diversas situações laborais. A metodologia, embora envolvam conteúdos potencialmente significativos, é comum se ver escolas na quais esses não tenham sido simuladas, por qualquer que seja o motivo, durante toda a trajetória acadêmica. Esse método de ensino aprendizagem promove a "formação" de profissionais digitalmente fluentes e capazes de aprender a aprender e levar outros a fazerem isso de forma autônoma.

Trata-se de uma aprendizagem que permite aos profissionais, de acordo com Delors (2010), adaptar-se diante do desconhecido, do inesperado, em face às constantes mudanças da sociedade, sem negligenciar os conhecimentos básicos já consolidados. Noutros termos, uma aprendizagem que permite aos sujeitos que dela participam imergir no velho para descobrir o novo, de modo a refletir, indagar a si próprio, indagar aos outros, estabelecer associações e assim, encontrar maneiras de solucionar problemas nos mais diferentes níveis e graus de complexidade. 
2. Desenvolvimento Da Vivência Em Uma Experiência Assistida

Esta experiência vivenciada se deu com as alunas do Curso de Pedagogia, da faculdade de Tecnologia Eniac relacionando os conteúdos de ensino com alguns tópicos da informática. Eles foram escolhidos como insumo para o trabalho que se pretendia realizar. A escolha, considerou diversos conteúdos de ensino, do eixo comum, trabalhados dentro de diferentes cursos, independente de área do conhecimento.

Por se tratar da primeira turma do curso de pedagogia que ingressou no período de julho a agosto de 2015, a experiência vivida se deu de forma experimental, em paralelo às unidades curriculares que compunham o módulo básico da Gestão da Educação. As unidades foram: Comunicação e Expressão, Políticas Sociais e Ambientais, Organização e Processos Gerenciais em Educação, Modelos de Gestão Educacionais, Informática Aplicada, Matemática, e os Seminários de Gestão da Educação no Projeto Integrador.

Uma vez conhecidos os temas, a abordagem de ensino, a aprendizagem dos conteúdos pelo público alvo foi se fazendo na vivência - o planejado conferindo descobertas, inovações, imersões e transformações.

A descoberta da metodologia - Descobrir significa encontrar algo ou alguém, é tirar a capa daquilo que estava encoberto, e conhecer pela primeira vez. Isto se faz, muitas vezes, pelo envolvimento casual dentro de uma situação problema que demanda resolução. A partir do envolvimento, embasado em conhecimento já consolidado - o velho - e na necessidade ou curiosidade em descobrir, ocorre o despertar da indagação e da investigação, o que conduz ao descobrimento do até então desconhecido - o novo. Partindo deste pressuposto entende-se que, tanto o professor quanto o ambiente de ensino e aprendizagem devem proporcionar alternativas para percepção dos alunos e suas descobertas. É importante ressaltar que cabe ao professor saber, a priori, aquilo que deseja que seus alunos descubram de modo a promover reflexões e espaços que facilitem esta descoberta. Por meio das tradicionais rodas de conversa as alunas do curso de Pedagogia da descobriram as Metodologias Ativas e, do mesmo modo, as Tecnologias Digitais inovadoras que seriam empregadas no decorrer da trajetória acadêmica. A relação desta dupla, Metodologia \& Tecnologia, resulta na graduação do pedagogo.

$\mathrm{O}$ encontro que viabilizou a roda de conversa recebeu o nome de Café Pedagógico. O primeiro de muitos encontros com as alunas do Curso de Pedagogia e aconteceu no dia 22 de agosto de 2015 na sala Google EniacLab, localizado no andar térreo, espaço digitalmente inovador que serviu de lócus para os encontros. Após uma dinâmica alunas e professores seguiram para um café da manhã oferecido pela Faculdade. 
Figura 1: Metodologias Ativas com a Pedagogia Roda de Conversa na Sala Google EniacLab da faculdade de Tecnologia Eniac FAPI. Foto do Encontro do Problem Based Learning - PBL

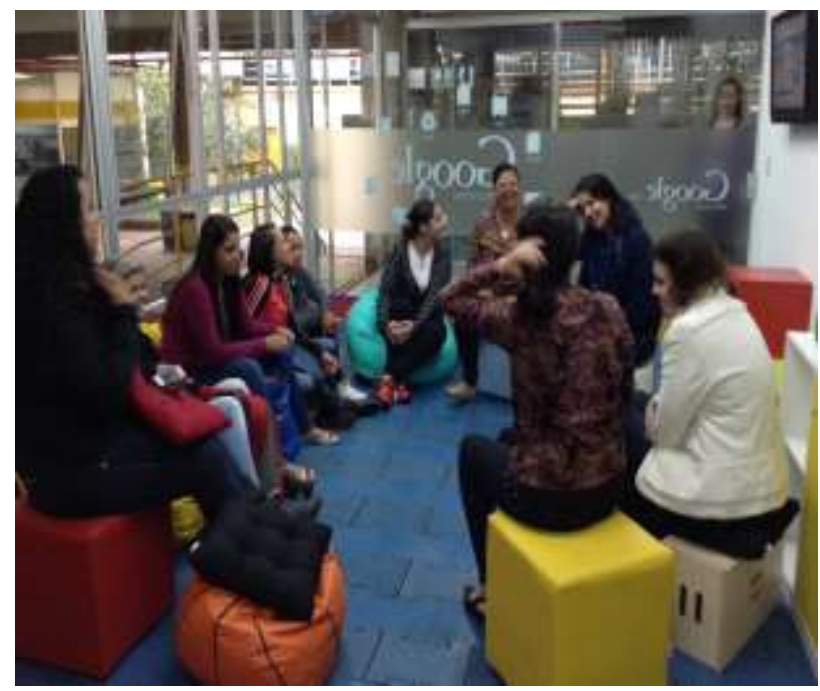

Fonte: Foto produzida pelos alunos da Faculdade Eniac de Guarulhos SP, em 2015.

Figura 2: Metodologias Ativas com a Pedagogia Café Pedagógico. $1^{\circ}$ Encontro

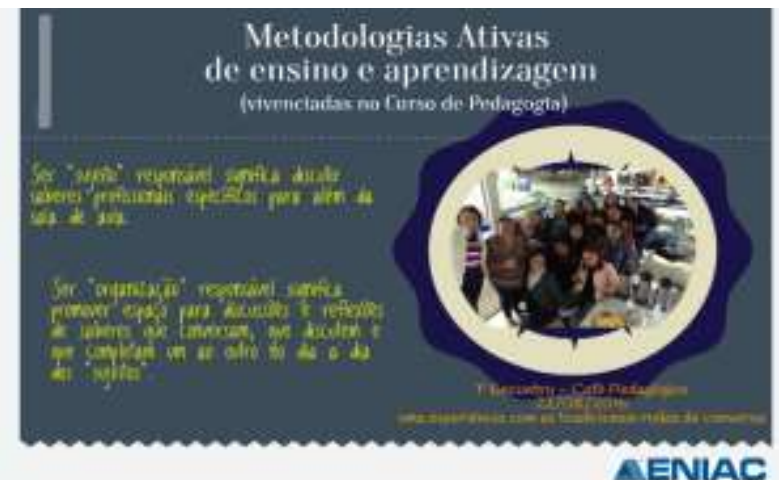

Fonte: Analisado pelos autores na Faculdade Eniac Guarulhos SP, em 2015. Disponível em: https://magic.piktochart.com/output/7468039metodologias-ativas-com-a-pedagogia-revisitandoas-rodas-d
Durante o Café Pedagógico, alunos e professores conversaram descontraidamente e conheceram um ao outro com maior aprofundamento, apresentaram suas concepções sobre o Curso de Pedagogia e sobre sua proposta "formativa". Discutiram sobre o papel do pedagogo, nas escolas e fora delas. Também, sobre o uso de tecnologias digitais no dia a dia das pessoas. Além disso, foi por meio do Café Pedagógico que as alunas conheceram sobre as Metodologias Ativas de ensino e aprendizagem, suas características principais e contribuições para a "formação" profissional. Ao final deste encontro, as alunas foram convidadas a buscar e refletir, em casa, sobre o uso das TICs como ferramentas de trabalho do pedagogo. O segundo encontro batizado de Nas nuvens com as TICs aconteceu em 28/08/2015, durante a aula de Informática Aplicada, em parceria com a professora responsável pela ministração desta unidade curricular.

Inovação de antigos costumes, tradições, processos

\section{Inovar significa modificar antigos} costumes, tradições, processos, muitas vezes, enraizados pelo tempo. É criar uma novidade, “oxigenar o antigo" e que talvez, já não atenda mais. Para isto é preciso considerar a ideia de que inovação não significa descartar o passado e projetar o futuro. Muitas vezes, é preciso conhecer o passado, para entender sobre determinada coisa e seu processo evolutório. Em face deste entendimento, antes mesmo de se 
discutir sobre o uso das TICs como ferramentas de trabalho do pedagogo, em primeiro, se discutiu sobre a informática, tão somente, sua evolução ao longo dos tempos e consequente penetração em nosso dia a dia. Como tonar este encontro inovador foi o primeiro dos desafios. Assim, ao invés de uma tradicional aula expositiva dialogada, o conteúdo foi discutido a partir de um Infográfico, um documento digital disponível online na web e contendo apenas os principais pontos que se julgou necessário a esta discussão e a proposta deste segundo encontro.

Figura 3: Metodologias Ativas com a Pedagogia - Discutindo a Informática. Parte do $2^{\circ}$ Encontro.

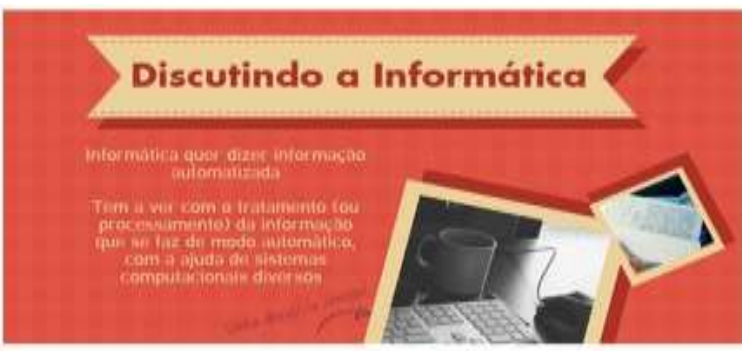

A Informática evolui com o tempo

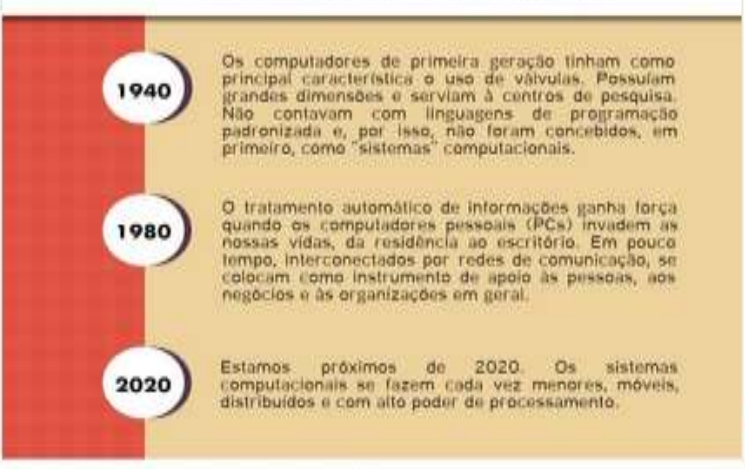

Wearable Technology

The Internet of Things

SMARTCITIES

Ubiquitous Computing

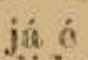

realidade

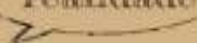

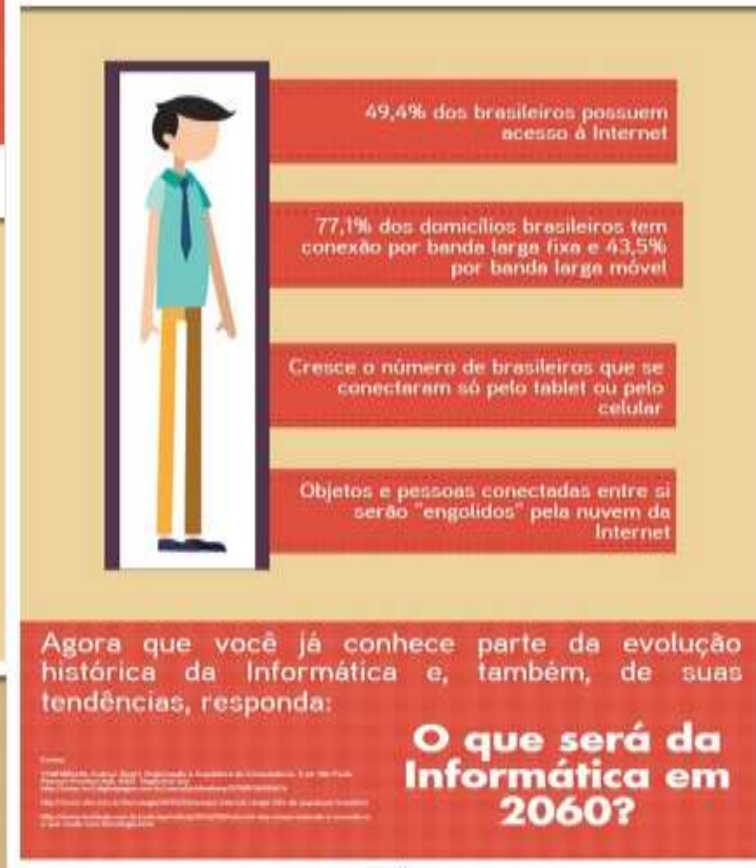

E.af Piktochart

Fonte: Analisado pelos autores na Faculdade Eniac Guarulhos SP, em 2015. Disponível em: https://magic.piktochart.com/output/6952093-infografico-discutindo-a-informatica

Novas mídias digitais precisam fazer com que "bons e velhos assuntos" sejam apresentados aos alunos de forma mais agradável e, como consequência, mais cativante. A resistência em utilizar recursos tecnológicos digitais ainda é grande, seja no âmbito acadêmico ou corporativo. Embora haja forte discussão sobre o uso de recursos como extensores de nosso corpo ainda existem àqueles que se sentem inseguros $\mathrm{e}$ desmotivados em tê-los como aliados. Em 
disciplinas ou unidades curriculares que tratam sobre a Informática é comum que o professor ou instrutor em sala de aula (ou laboratório de informática) proceda com determinada explicação acerca do uso de um aplicativo (ou software) em específico e, depois, como tarefa de casa solicite aos seus estudantes o desenvolvimento de um produto qualquer, elaborado a partir do aplicativo discutido em sala de aula. O faz, na tentativa de promover alternativas para que seus alunos "mergulhem fundo" no aplicativo, que reflitam, questionem, descubram e, assim, construam novos conhecimentos.

\section{A Imersão no Processo}

Imergir significa mergulhar, ir fundo a procura de algo, se aprofundar, a fim de que deste mergulho se tenha aquilo que, até então, não se tinha, aquilo que não era conhecido, bem provável, algo novo, a exemplo de um novo conhecimento. O novo, por suposto, nos é desconhecido. E o desconhecido, em geral, assusta, muitas vezes, provoca resistências, desconfortos e outros, até que se torne conhecido. Por isso, é preciso fazer deste processo, do desconhecido ao conhecido, um processo prazeroso, confortável e não resistivo. Então, por que não imergir juntos? Esta foi a resposta encontrada para atender ao segundo desafio do encontro Nas nuvens com as TICs.

Aqui, uma estratégia adaptada de sala de aula invertida - ou flipped classrom, foi adotada. Originalmente, a estratégia de sala de aula invertida prevê que o aluno estude o conteúdo de ensino em casa, por meio de recursos digitais interativos, e na sala de aula, com seus pares e professores, aproveite o tempo para tirar suas dúvidas e desenvolver atividades mais complexas que envolvam o conteúdo estudado. Em casa, ao seu tempo, quando o aluno se encontra com o aplicativo estudado em sala, bem provável, surjam dúvidas, também, descobertas. Só que neste tempo e espaço, em geral, o aluno está sozinho e não tem com quem dialogar sobre suas dúvidas, tampouco, com quem comemoras suas descobertas. 
Figura 4: Metodologias Ativas com a Pedagogia - Construindo presencial e colaborativamente. Parte do $2^{\circ}$ Encontro.
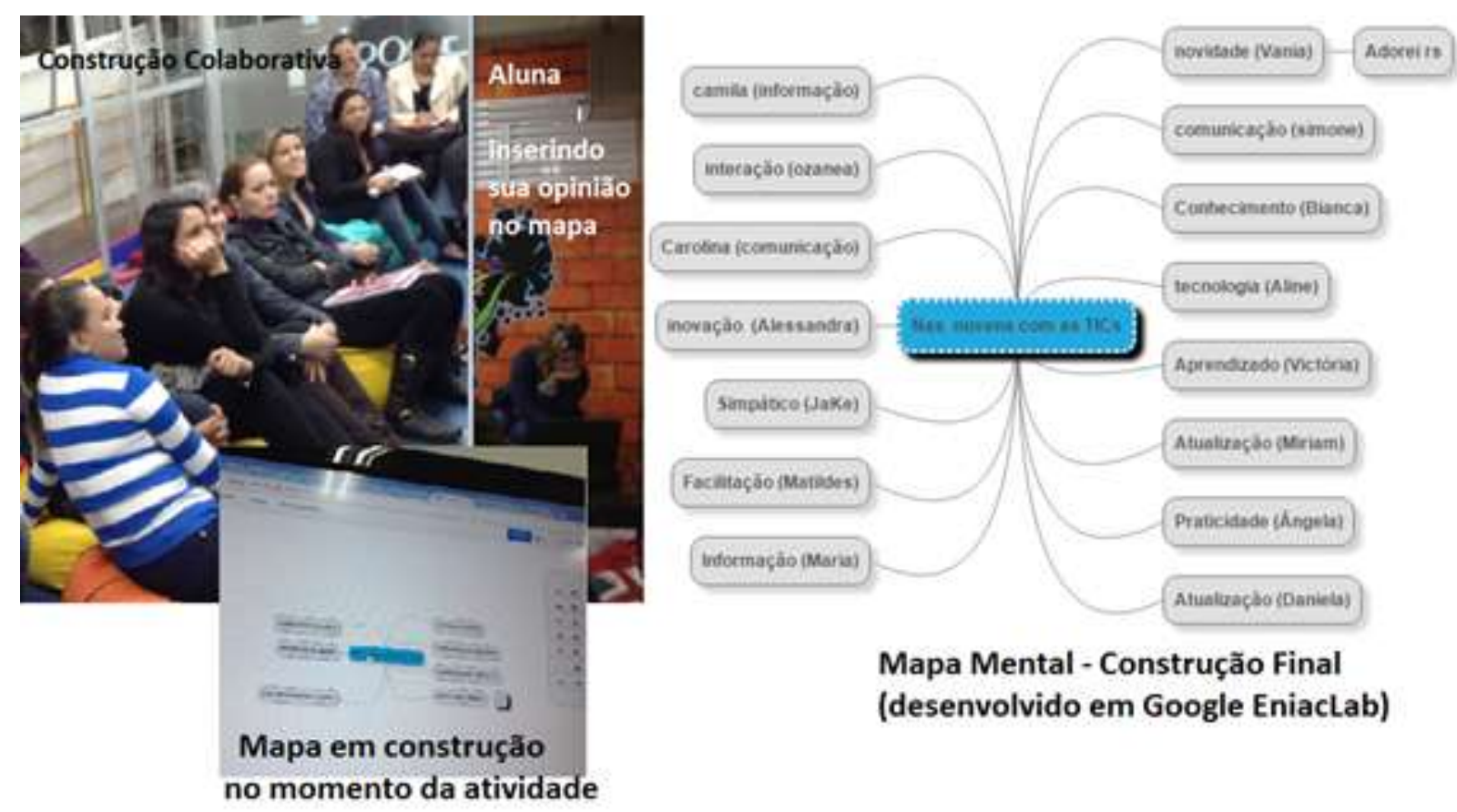

Mapa Mental - Construção Final (desenvolvido em Google EniacLab)

Fonte: Elaborado pelos autores na sala google Eniaclab da Faculdade Eniac de Guarulhos SP, em 2015.

Em face deste entendimento, as alunas do Curso de Pedagogia da Faculdade de tecnologia Eniac FAPI foram convidadas a ocupar, novamente, a sala Google EniacLab, para construir online e de forma colaborativa, tanto na perspectiva virtual quanto física, um mapa mental para descrever suas impressões sobre as novas ferramentas digitais descobertas por meio deste encontro. A proposta é que elas possam descrever as impressões sobre o método ativo e invertido de ensino e aprendizado que estão experimentando.

O MindMup foi a ferramenta utilizada para a construção colaborativa do mapa mental. Este sistema é classificado como uma ferramenta digital online gratuita para organização de ideias através de mapas mentais e pode ser conectado ao Google Apps. Um software para produtividade da Google Inc. que oferece um rol de aplicativos da web com recursos similares aos de pacotes de escritório tradicionais. É a união da tecnologia digital e a "formação" profissional, em mesmo tempo e espaço.

No relato do professor da experiência, a atividade, além de promover novo conhecimento, despertou diversão e quebra de barreiras. Foi tão importante que promoveu mútua colaboração entre as alunas. Algo que aconteceu com facilidade, como se estivessem com amigas em casa. Algumas alunas 
mencionaram que se a atividade de construção do mapa mental tivesse sido indicada para ser realizada como tarefa isolada em casa teriam desistido da mesma, ou teriam experimentado muitas dificuldades. É o frágil, que quando se junta, com verdade, se torna forte.

\section{A Transformação pelo método}

Transformar tem o sentido de modificar, de fazer diferente, de dar outra direção ou sentido, de dispor de outra forma, para renovar, para adequar, enfim, um processo que envolve grandes alterações, não somente físicas como também comportamentais. E assim são os processos de ensino e aprendizagem, corresponsáveis por profundas transformações, nos sujeitos, nos ambientes e nos processos de trabalho de "formação". Neste caminhar se dá a descoberta do desconhecido e o direcionamento ao conhecido. Possibilita o trajeto do erro ao acerto e do problema à solução. Isto não significa ignorar o desconhecido, apagar o erro e fugir do problema. Significa, descobrir sobre o desconhecido a partir da exploração deste se apoiando no erro para chegar ao acerto, mergulhando no problema para encontrar a solução. Uma das estratégias que se pode empregar para vivenciar esta transformação é o PBL -Problem Based Learning, a estratégia de ensino e aprendizagem ativos que tem como foco a aprendizagem baseada em presença dos problemas.

O PBL surgiu na década de 60, no âmbito da formação do profissional da área da saúde, nos
EUA, como resposta à frustação e ao descontentamento de alunos face ao elevado volume de conhecimentos entendidos como irrelevantes à prática médica (COLL, 2010). A estratégia trabalha com o conceito de resolução de problemas do cotidiano, em outras palavras, problemas reais e que envolvem, por exemplo, uma região em específico, um município, um estado, um país e, por que não, todo o universo, afinal, na atualidade, muito se fala sobre o mundo globalizado.

Embora as pessoas possam ter diferentes impulsos motivacionais, no âmbito da Educação, uma atividade educativa que se desempenha a partir da resolução de um problema real é, em geral, mais motivadora, por exemplo, do que uma de simples memorização ou exposição dialogada de conteúdos de ensino. O impulso motivacional varia de pessoa para pessoa. Ele pode ser explicado, de acordo com Chiavenato (2004), em função de uma hierarquia de necessidades humanas, conhecida como hierarquia das necessidades humanas de Maslow. Do primeiro ao quinto nível destacam-se as necessidades na ordem de urgência, primeiro as fisiológicas, segundo as de segurança, terceira, as sociais ou de amor, de afeto, afeição e sentimentos, em quaro lugar as de estima e, no topo da pirâmide, em quinto lugar as necessidades de auto realização. Neste quinto e último nível, exemplificam-se ações como moralidade, criatividade, espontaneidade, aceitação dos fatos, ausência de preconceitos e, também, soluções de problemas conforme Chiavenato (2004). 
A disposição hierárquica de necessidades de Maslow faz entender, ainda que seja provocada por uma necessidade humana de último nível, que a solução de um problema pode fazer com o uma pessoa se sinta motivada. No caso do aluno, a motivação nele provoca um impulso, que leva a interagir, o seu pensamento, com seu colega de turma ou professor, ele se coloca em movimento pelo aprender de um saber qualquer naquele momento. $\mathrm{O}$ problema a ser solucionado pode ser equivalente a um problema real, o aluno, uma vez motivado, consegue visualizar com maior facilidade e disposição o "por que" de aprender determinado(s) conteúdo(s) e, “onde" e "como" é possível utilizar aquilo que para ele, por si só, se aprende.

A prática do PBL já é realidade em várias instituições de ensino brasileiras, desde instituições que atuam única e exclusivamente com a Educação básica, até as de Ensino Superior. O PBL é, portanto, ao mesmo tempo, ferramenta e prática, baseada em evidências e que trabalha a partir da resolução de problemas do cotidiano. Para provocar o transformar desta "formação" um problema real, de caráter inovativo e interdisciplinar, foi apresentado às alunas do Curso de Pedagogia. A aprendizagem baseada neste problema permitiu, a partir de uma dificuldade real e contextualizada, conceber, organizar e produzir um painel a ser apresentado como mostra de trabalho na FENIAC, feira de habilidades técnicas e tecnológicas realizada pelo Colégio e Faculdade Eniac e que aconteceu nos dias 25 e 26 de Setembro de 2015.
Figura 5: Metodologias Ativas com a Pedagogia Construção do Painel. Parte do Encontro do PBL.
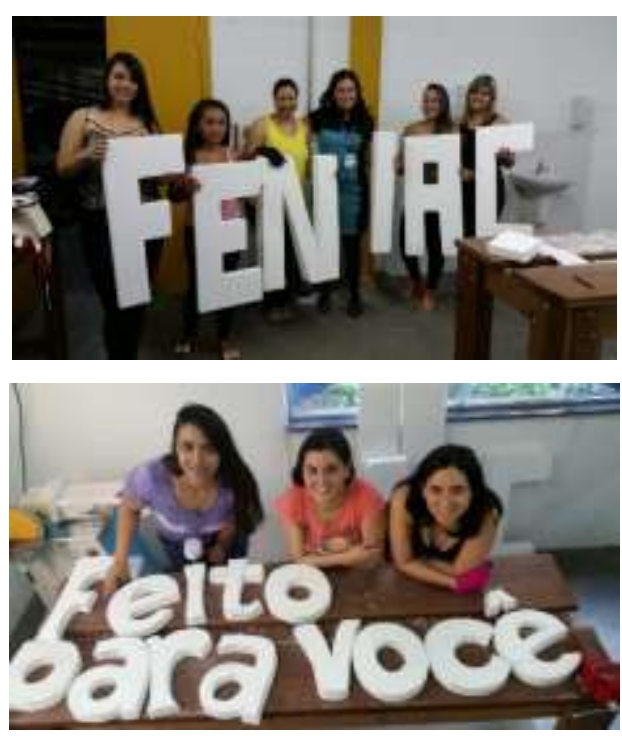

Fonte: Elaborado pelos autores, na Faculdade Eniac Guarulhos SP, em 2015.

Primeiro, o problema foi explicitado às alunas do Curso de Pedagogia. Na sequencia, reunidas em equipes, as alunas identificaram, de forma coletiva e com a inferência direta no documento digital, termos desconhecidos.

Figura 6: Metodologias Ativas com a Pedagogia Explicitação do Problema. Parte do Encontro do PBL

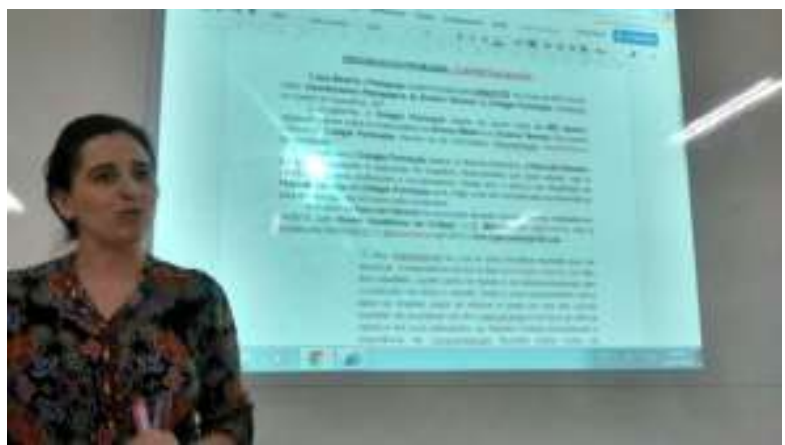




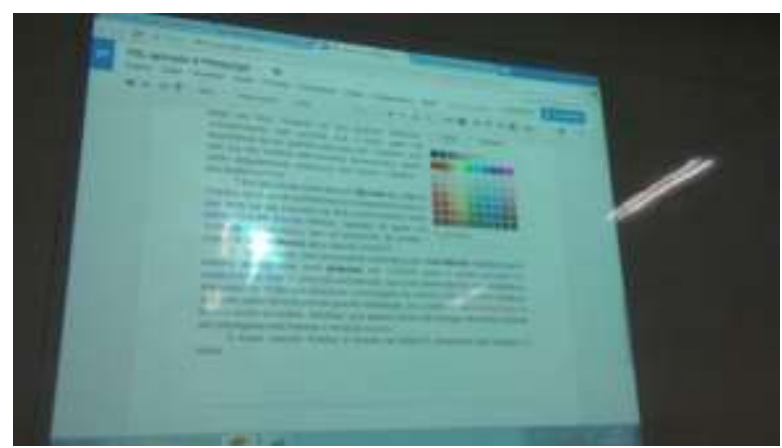

Fonte: Elaborado pelo autor - na Faculdade Eniac Guarulhos SP, em 2015

As discussões que se fizeram na sequencia, trouxeram à tona uma série de questões que levaram as alunas a buscar conhecimento em variadas disciplinas. As ideias para a confecção do painel fizeram discutir sobre dimensão, peso, sustentação e outros.

Figura 7: Metodologias Ativas com a Pedagogia Discussão de outras disciplinas (Parte do Encontro do PBL).

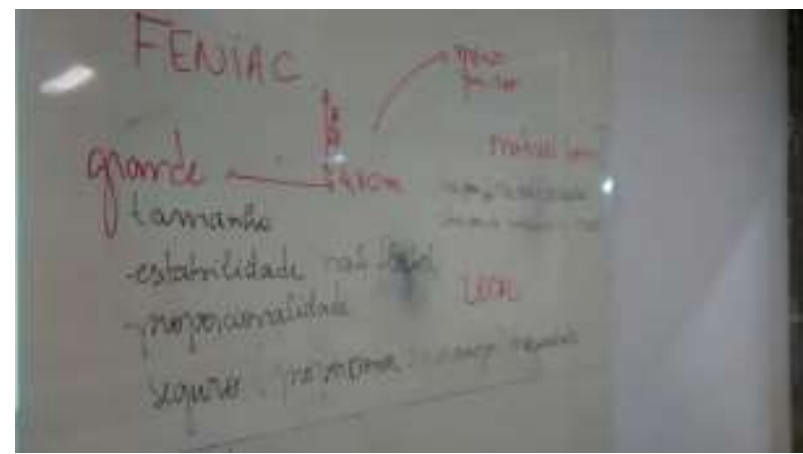

Fonte: Elaborado pelo autor - na Faculdade Eniac Guarulhos SP, em 2015

A pesquisa acerca das propriedades de materiais diversos como madeira, gesso, metal e outros. Uma interdisciplinaridade com a matemática e com a física básica, necessária, por suposto, às futuras pedagogas.
Figura 8: Metodologias Ativas com a Pedagogia Pesquisa de característica de madeirite compartilhada no grupo pelo whtasApp. Parte do Encontro do PBL.

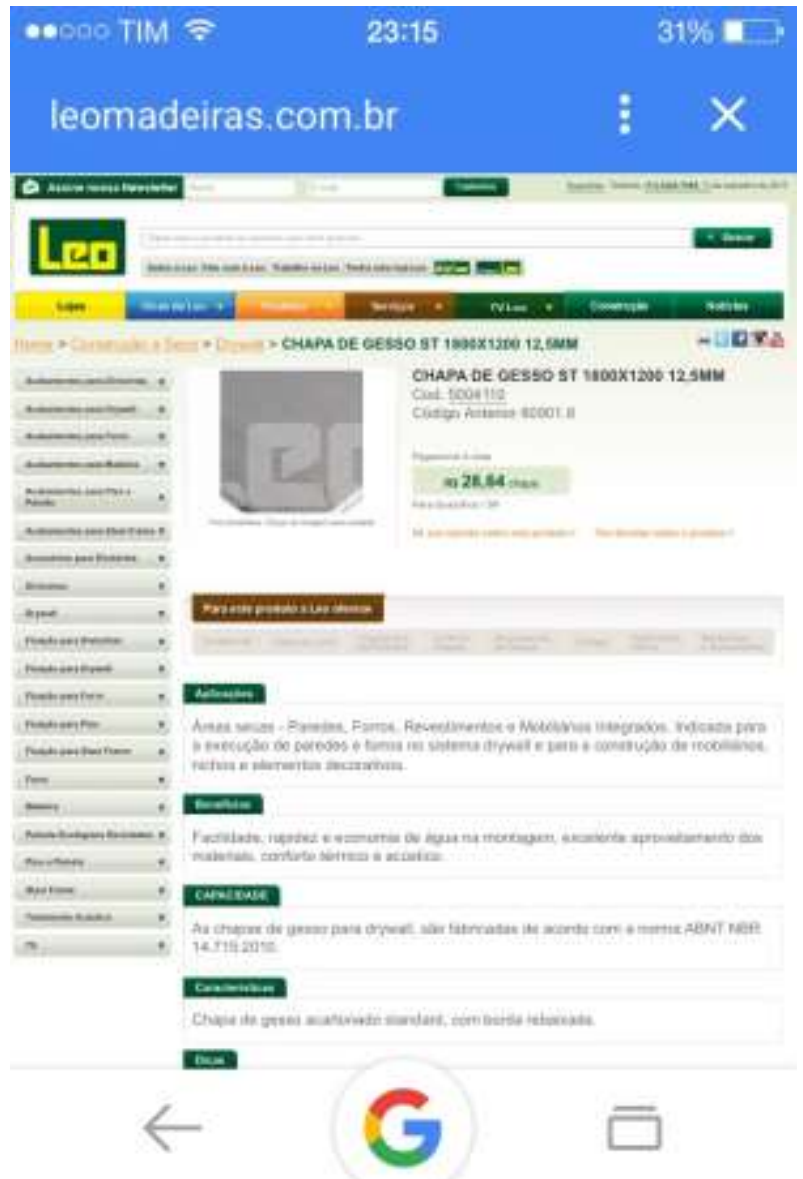

Fonte: Elaborado pelo autor - na Faculdade Eniac Guarulhos SP, em 2015

Figura 9: Metodologias Ativas com a Pedagogia Pesquisa de característica de iluminação alternativa realizada pelo Google. Parte do Encontro do PBL.

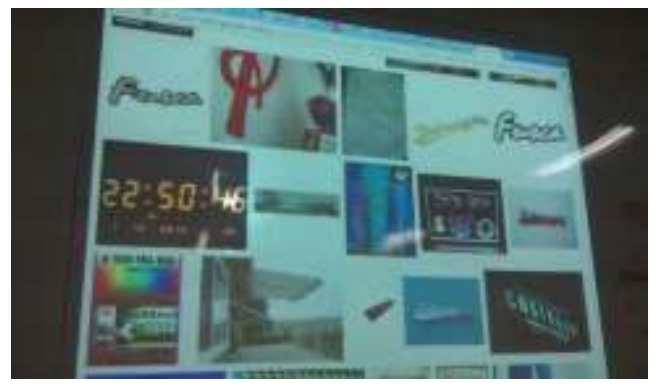

Fonte: Elaborado pelo autor - na Faculdade Eniac Guarulhos SP, em 2015. 
Uma vez acordado uma solução hipotética as alunas decidiram elaborar um protótipo em tamanho real para facilitar a visualização do painel.

Figura 10: Metodologias Ativas com a Pedagogia Construção do Protótipo em tamanho real. Parte do Encontro do PBL.
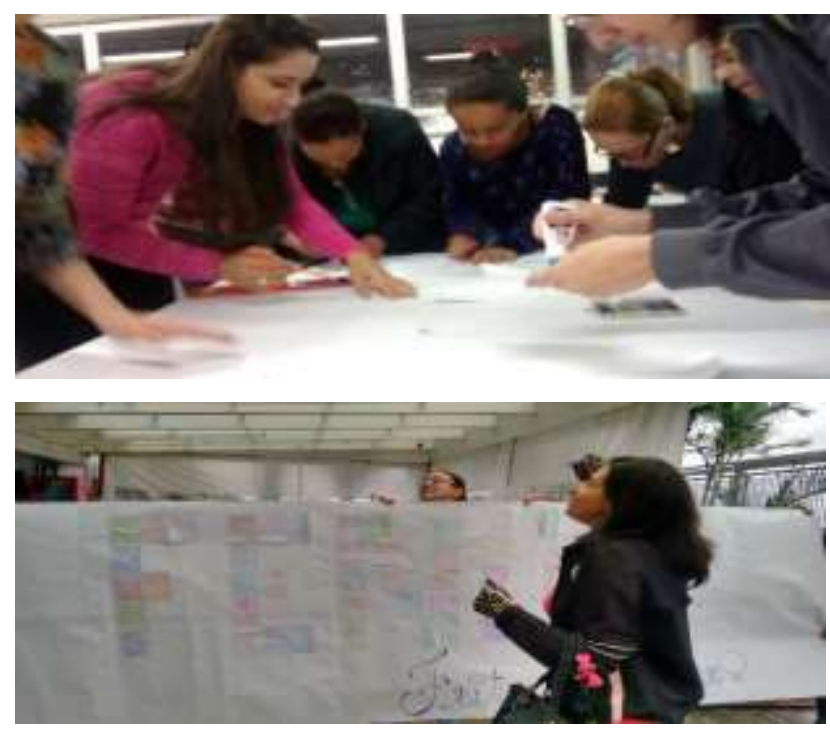

Fonte: Elaborado pelo autor - na Faculdade Eniac Guarulhos SP, em 2015

$\mathrm{Na}$ construção do painel houve forte integração com os alunos da turma de Engenharia Civil da Faculdade Eniac. Juntos, futuros pedagogos e engenheiros se reuniram no Laboratório de Maquetes para "dar vida" ao protótipo elaborado. Um movimento de integração pessoal e disciplinar que promoveu descobertas, imersões, inovações e transformações e que fizeram estes profissionais, construir conhecimento de modo coletivo, colaborativo e divertido.
Figura 11: Metodologias Ativas com a Pedagogia Integração da Pedagogia com a Engenharia. Parte do Encontro do PBL.

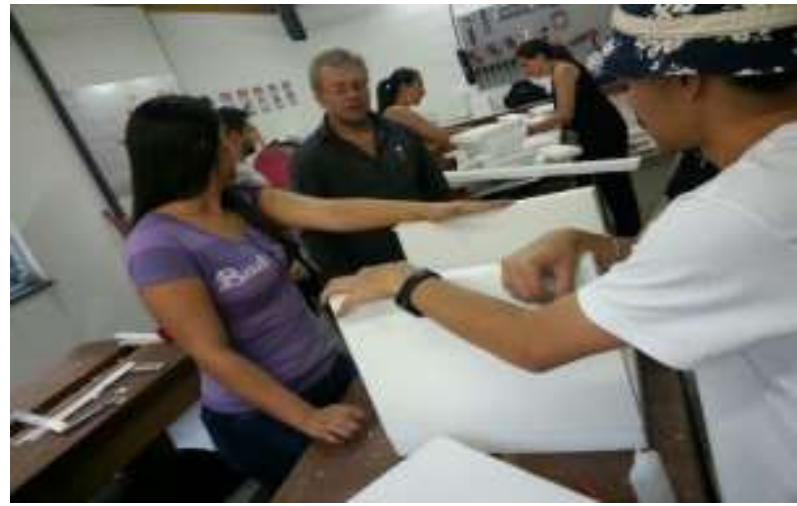

Fonte: Elaborado pelo autor - na Faculdade Eniac Guarulhos SP, em 2015

Todas as estratégias de ensino e aprendizagem aqui descritas permitem combinar o individual com o coletivo, o presencial com o a distância, a teoria com a prática, a concepção com a execução e fazem parte, todas elas, de um ensino mesclado. Noutros termos, um ensino híbrido e que traz em seu bojo a ideia de que é possível planejar arranjos acadêmicopedagógicos que combinem diversas estratégias de ensino e aprendizagem concomitantemente. Alguns destes arranjos são vistos como um par que se complementa de forma harmônica, outros, no entanto, podem ser vistos como um par que discorda um com o outro. Neste ponto, interessante lembrar o pressuposto defendido por Takeushi e Nonaka (2004, p.19) de que "as contradições, as inconsistências, os dilemas, as dualidades, as polaridades, as dicotomias e as oposições não são alheios ao conhecimento, pois o conhecimento em si é formado por dois 
componentes dicotômicos e aparentemente opostos - isto é, o conhecimento explícito e o conhecimento tácito" (Takeuchi \& Nonaka, 2004, p.19).

Além disto, e, tão importante quanto, é necessário o entendimento de que toda estratégia de ensino e aprendizagem precisa estar embasada em tópicos, objetos ou conteúdos de ensino teoricamente fundamentados, ainda que o aluno não reconheça de imediato a importância de tal fundamentação. Neste ponto, cumpre observar que, em um primeiro momento, é o professor quem sabe aquilo que o aluno precisa conhecer para então compreender e fazer uso daquilo que se conhece. Para determinar esta demanda o professor precisa perguntar a si mesmo: o que eu professor quero que meu aluno faça com este conhecimento, com este saber? Conteúdos de ensino elencados, plano de aula elaborado, faz-se a hora de trabalhá-los com os alunos a partir de um problema socialmente contextualizado, conduzindo-os à resolução do mesmo. Trata-se de métodos, estratégias e recursos que se interrelacionam com vistas ao êxito do processo de ensino e aprendizagem e a "formação" integral do homem.

\section{Considerações Finais}

Como qualquer método "formativo", o método de ensino e de aprendizagem ativo também necessita de estratégias e recursos. $\mathrm{Na}$ descoberta de como selecioná-los adequadamente, está o segredo do sucesso Não existe uma resposta pronta e acabada. Cada pessoa precisa encontrar a sua própria maneira. Ao fazê-lo preciso ter a coragem de assumir os erros, a humildade para reconhecê-los e a força para levantar e seguir em frente sempre recomeçando. Esta ação desempenhada com o objetivo de, fazer aprender, precisa ser apreciada pelos participantes da ação. $O$ resultado idealizado, o produto do projeto, o serviço a ser consumido ou protótipo a ser desenvolvido, deve ser concebido como o fio condutor da prática docente. Esta, uma vez entendida permite que toda a problemática que envolve o processo de ensino aprendizagem ativos, precisa ser significativamente contextualizado. Este caminhar deve ser feito com humildade, compartilhando erros, acertos e rearranjos, com ênfase no "como" e fazendo uso de metodologias ativas na "formação" dos futuros pedagogos da instituição estudada.

Esta pesquisa não poderia ser realizada sem a colaboração sem a colaboração das alunas e professores do Curso de Pedagogia da Faculdade de Tecnologia Eniac FAPI. Ao professor José Carlos Guerra Júnior, Coordenador dos Cursos de Arquitetura, Urbanismo e Engenharia Civil da Faculdade, aos alunos do $2^{\circ}$ semestre de 2015 da unidade curricular de Maquetes, Neide Oliveira e Ericka Scarlassare da Diretoria Administrativa e todos os demais profissionais envolvidos na experiência aos quais os autores agradecem. 
4. Referências Bibliográficas

CHIAVENATO, Idalberto. Administração nos novos tempos. $2^{\text {a }}$ ed, Rio de Janeiro: Elsevier, 2004.

DEMO, Pedro. Formação permanente e tecnologia. 8a .ed. Ed, Petrópolis RJ. 20014.

MICHAELIS, Moderno Dicionário da Língua Portuguesa. São Paulo: Editora Melhoramentos, 2009.

MONereO, C. Coll. et al., Psicologia da educação virtual: aprender e ensinar com as tecnologias da informação e da comunicação. Porto Alegre - RS: Artmed Ed. S.A., 2010.

TAKEUCHI, H Nonaka, I. Gestão do conhecimento. $2^{\mathrm{a}}$.ed, Porto Alegre RS: Bookman, 2004.

\section{Referências Eletrônicas}

Boletím Tecnico Senac: a R. Educ. Prof., Rio de Janeiro, v.34, n.2, maio/agosto de 2008. Disponível em: http://www.oei.es/pdf2/habilidades-seculoxxi.pdf. Acesso, 15/09/15, 22h00

DELORS, J. Um tesouro a descobrir: relatório para a UNESCO da comissão internacional sobre Educação para o século XXI, 41 pp, Julho de 2010. Disponível em: http://unesdoc.unesco.org/images/0010/00109 5/109590por.pdf. Acesso, 15/09/15, 23h55min.
Discutindo

informática:

https://magic.piktochart.com/output/6952093infografico-discutindo- a-informatica Acesso, 15/09/15, 20h35min. 